
RTIGOS 



\section{Política de facção e ruralidade em Puna Jujeña, Argentina'}

\section{Factional politics and rurality in Puna Jujeña, Argentina}

\section{Carlos Cowan Ros}

Investigador adjunto, CEUR-CONICET, Argentina. Doutor em Ciências, UFRRJ. Última publicación: COWAN ROS, Carlos. Política, modos de vida y sociabilidad en una pequeña sociedad rural. Mundo Agrario, FHCE-UNLP, v. 18, n. 37, e046, abril 2017 y COWANROS, Carlos. Quando o "beneficiário" se personaliza-se. Revista Sociedade e Estado, UB. v. 29, n. 2, 2014.

\section{Resumo:}

No artigo analisa-se o processo de constituição de Fermín como o principal dirigente político de uma pequena localidade rural situada na Puna Jujeña, as condições de emergência e reprodução da facção que ele conduz e as características que adquiriu a institucionalidade estatal no lugar a partir de suas ações e de seus seguidores. A estratégia analítica e narrativa centra-se na trajetória de Fermín e o período de análise abarca desde seu nascimento, em 1950, até 2016. Dentre as conclusões, destaca que a emergência e constituição de Fermín como liderança política ocorreram em relação com transformações institucionais, sociais e econômicas. O reduzido peso eleitoral da localidade no cenário político provincial é uma característica estrutural que condiciona as práticas dos dirigentes políticos e suas projeções na hierarquia partidária. No entanto, observa-se sua capacidade na produção de vínculos com dirigentes políticos e agentes estatais de diferentes níveis de governo, por dentro e por fora da estrutura partidária, e na ressignificação e produção de instituições estatais para viabilizar sua gestão de governo e sua reprodução na estrutura política.

Palavras-chave: Facção, Práticas Políticas, Trajetória Política, Estado.

Agradecimientos: Para este estudio se recibió apoyo institucional y financiero del Consejo Nacional de Investigaciones Científicas y Técnicas (PIP 112-20150100247-CO), de la Agencia Nacional de Promoción Científica y Tecnológicas (Proyecto PICT 2014-2676) y de la Fundación Facultad de Agronomía de la UBA. Agradezco a los pobladores de la comarca de Yavi por su disposición a compartir sus vivencias y cotidianeidad. 


\section{Abstract:}

The paper analyses the rise of Fermin as the most important political leader of a rural village located in Puna Jujeña, the conditions that enable the emergence and maintenance of the faction that he conducts and the characteristics acquired by the state institutions in the town as the result of the political practice of the faction members. The analytic and narrative strategies focus on Fermin's trajectory. The period of analysis covers from his birthday in 1950 until 2016. On the conclusions it is observed that Fermin's emergence and constitution as political leader were in relation to the institutional, social and economics transformation that took place. The scarce number of electors in the village when compared to the province's political scenario is a structural characteristic that limits the practices of those political leaders and their future projections on the hierarchy of political party. Nevertheless, we observe their capacity for producing ties with political leaders and state technician at different governs levels, inside and outside the political party, and for producing state institutions and improving their governance and the reproduction of their position in the political structure.

Keywords: Faction, Political Practices, Political Trajectory, State.

\section{INTRODUCCIÓN}

Entré por cada comunidad, pero de a poco. Hablando con un amigo, hablando con otro, convenciendo a la gente de cómo se tendría que manejar el Municipio. ¡Concientizando, pero recontra bien! Después me tomaron cariño, porque yo traté mucho a la gente, la traté bien. Nunca he sido una persona mala. Yo fui con todo el mayor respeto ${ }^{2}$.

Así relataba Fermín , creador y líder de la "línea" que gobierna hace más de 25 años la Comisión Municipal de Yavi", cómo "se metió en política". En

\footnotetext{
2 Las comillas dobles (“...”) refieren a enunciados y términos de mis interlocutores y de otros autores.

Los nombres son ficticios para preservar la identidad de las personas.

4 En la provincia de Jujuy la administración de los gobiernos locales se organiza en intendencias, cuando la población de la jurisdicción supera las 5.000 personas, y comisiones municipales, cuando es inferior
} 
las cuatro charlas que tuvimos entre el 2005 y el 2016, siempre encontró la excusa para instruirme sobre la clave de su éxito: "La política es, un poco, tener cariño, respeto y voluntad de ayudar a la gente y, otro poco, trabajar". Para él, es esa fórmula la que aún lo tiene al frente de la escena pública local. También lo es para "sus" dirigentes, que me la recordaron en cada entrevista que me concedieron.

Las narrativas de los yaveños que asumen papeles políticos se distanciaban de los discursos doctrinarios, programáticos y/o ideológicos que suelen atribuirse a la política. La figura caricaturesca del político cínico, manipulador y distanciado del resto de la sociedad, difundida por los medios de comunicación y naturalizada en parte de la academia, se desdibujaba para comprender las prácticas políticas locales. Impregnada de contenidos morales y afectivos, la política yaveña me interpelaba a abandonar presupuestos apriorísticos y normativos, para aprehenderla e interpretarla a partir de las dinámicas históricas, marcos contextuales y de las vivencias de sus protagonistas.

La "línea" de Fermín posee gran parte de los elementos con los que se conceptualizó la idea de facción en la Antropología, a partir de la década de 1960. En oposición a grupos corporativos y/o institucionalizados, caracterizados por cierta formalización de normas, las facciones fueron definidos como unidades de conflicto informales articuladas en torno a un líder o ego, quien recluta a sus seguidores a partir de diferentes principios de filiación y (re)produce sus vínculos por medio de transacciones personales, con el fin de disputar recursos públicos (MAYER, [1966] 1980; RALPH, 1966; entre otros).

A partir de la década de 1990, el giro interpretativo operado en las ciencias sociales revalorizó la subjetividad de los individuos, a través de poner en relación significados y prácticas. Los denominados "estudios morfológicos" de las sociedades y, por derivación, la noción facción cayeron en desuso. El nuevo abordaje problematizó modelos apriorísticos con los que

\footnotetext{
a dicha cifra. La Comisión Municipal de Yavi se encuentra en el norte de la provincia, extremo norte de Argentina. Localizada en la región altiplánica andina Puna, la comarca está conformada por la localidad de Yavi, "el pueblo", y doce aldeas o "comunidades" aledañas, área referenciada por los lugareños como "el campo". Su población residente es inferior a los 2.000 habitantes, por lo que es considerada rural por el Instituto Nacional de Estadísticas y Censos (INDEC, 2012).
} 
se suele pensar la política. La representación de lo político como un campo social autónomo y con características universales pasó a ser tensionada por enfoques que objetivan su especificidad a partir de caracterizar su temporalidad, imbricaciones con otros ámbitos sociales y los sentidos y prácticas agenciadas por los protagonistas (BALBI; ROSATO, 2003; PALMEIRA; HEREDIA, 2010). Los modelos analíticos que reducen el comportamiento político a un proceder individual, racional e ideológico comenzaron a ser interpelados por abordajes que evidencian cómo se imbrican con esas fuentes de la acción social contenidos morales, emocionales y/o lúdicos (GOODWIN; JASPER; POLLETA, 2000). A partir de problematizar enfoques reificantes del estado e interpretarlo como un artefacto cultural, las prácticas cotidianas de personas que ocupan posiciones subalternas comenzaron a ser reconocidas e integradas a las desplegadas por quienes conducen las agencias estatales en la comprensión de la producción de las formaciones estatales (JOSEPH; NUGENT, 2002; DAS; POOLE, 2008).

En Argentina, en la década pasada, adquirieron relevancia los estudios etnográficos sobre prácticas políticas. Con la denominada “Crisis de 2001", surgió el interés por comprender las lógicas con las que individuos y organizaciones urbanas articulaban sus estrategias de sobrevivencia y sus prácticas políticas, ante la precarización de sus condiciones de existencia. En los estudios rurales la política despertó menor entusiasmo. Lo rural ha sido abordado fundamentalmente desde su dimensión económica, lo agrario. Ante la disminución de la población rural del país, la política de las pequeñas localidades cada vez tiene menor incidencia en las elecciones provinciales y nacionales. No obstante, estudiar las representaciones, lógicas y estructuras que se despliegan en torno a la misma posibilitan comprender los modos como se expresan y (re)producen las estatalidades en los ámbitos rurales, así como la configuración de grupos sociales, de sus estrategias de vida y sus interacciones con las dinámicas sociales que allí operan, incluyendo las agrarias.

En este artículo aporto a la comprensión de las especificidades que adquiere la política en localidades rurales, inspirado por las perspectivas analíticas referenciadas arriba. Analizo el proceso de producción de Fer- 
mín como dirigente político, las condiciones de surgimiento y reproducción de la facción que conduce y estatalidades que emergen de sus prácticas y de las de sus seguidores. La estrategia analítica y narrativa focaliza en la trayectoria de Fermín, por lo que el periodo de estudio abarca desde su nacimiento en 1950 a 2016. La primera etapa de recolección y análisis de datos ocurrió entre 2004 y 2008, en el marco de mi tesis doctoral (COWAN ROS, 2013), en la que estudié las prácticas políticas en Yavi. El interés por los fenómenos observados me motivó a continuar la recolección de datos hasta $2016 .^{5}$

\section{“METERSE EN POLÍTICA”}

“PPara ser político, primero hay que ser embustero!” Con esa frase, una anciana pretendió finalizar una conversación entre vecinos y dispensarse de revelar su voto en las próximas elecciones. Lejos de ser una apreciación individual, entre los yaveños prevalece una percepción negativa de la política y de los políticos, vinculada al atributo de indecencia. Ante esa idea generalizada, por qué un miembro de una pequeña localidad que goza de cierta reputación habría de incursionar en un ámbito concebido a priori como inmoral. ¿Por qué Fermín se "metió en política"?

Nací en el Ingenio San Martín del Tabacal [Orán, provincia de Salta], donde mi viejo emigraba desde acá a la cosecha de caña. Después, me crié en Yavi. Viví acá en Yavi y actualmente sigo viviendo en Yavi. Ha sido una época en la que yo también emigraba desde acá hacia la zafra [de caña de azúcar], por la situación de trabajo; uno tiene su ética de trabajo. (...) Lo anterior era que en el mes de mayo la gente iba desde acá a la zafra, estábamos seis meses de trabajo y nuevamente emigrábamos para acá.

\footnotetext{
La información empírica fue relevada a partir de ocho viajes a Yavi, en tiempos electorales y no electorales, en los que entrevisté a dirigentes políticos de las distintas facciones, seguidores, electores, dirigentes sociales y técnicos de instituciones públicas y privadas de desarrollo. Algunas personas fueron entrevistadas en dos, tres o cuatro oportunidades. En la ciudad de Buenos Aires entrevisté a técnicos/as de programas de desarrollo rural ejecutados en Yavi.
} 
Al narrar la primera etapa de su vida, Fermín retrata la cotidianeidad de gran parte de los yaveños en la segunda mitad del Siglo XX, después que el presidente Juan Domingo Perón mejorase las condiciones laborales en los ingenios azucareros y pusiera fin a la coacción que los empresarios ejercían sobre los puneños ${ }^{6}$. Finalizado el último año de la escuela primaria, los niños comenzaban a emigrar junto a sus padres. En ese transitar entre Yavi y el ingenio se configuraba un colectivo social - "los zafreros" - con un modo de vida específico, que articulaba la venta de mano de obra de mayo a noviembre en el ingenio con la producción agropecuaria para el abastecimiento familiar en sus comunidades el resto del año, existiendo escasa diferenciación social en la comarca. Pero, al contarme cómo "se metió en política", Fermín reconoce otro nacimiento, en otro papel social, como hombre político.

Yo nací un poco allá, en los ingenios, cuando trabajaba en la cosecha de
caña. Las empresas nos estaban saboteando, no te pagaban bien. Uno era
el jornal que te saboteaban, otro era el tema del precio de caña, que te
pagaban muy poco, y otra porque te estafaban el kilaje. A uno le dolía,
porque uno lo sufre carnalmente. Uno tiene que sufrir los calores, la
lluvia... Da bronca, porque te engañan y hay gente tan humilde... La
mayor parte de la gente de la zafra era analfabeta, no sabía leer ni es-
cribir. Entonces, yo nazco de ahí, con mi cuñado, tratando de sacar al
frente a la gente. Conocí unos amigos que eran gremialistas. Cuando
yo inicio esto, ha crecido un sindicato nuevo frente a la empresa El Ta-
bacal, que era el Sindicato del Surco, que es únicamente de gente que
hacha caña, nada más. Entonces ahí empezamos nosotros a meternos
un poco en los gremios. Empecé a manejar políticamente con gente
de la parte política, porque los gremios también tienen una parte po-
lítica. Ahí aprendí un poco a meterme en política. Bueno, ahí nací yo.

Fermín se vincula a la actividad gremial con 31 años y como cabeza de una familia en expansión, con tres hijos. Corría el año 1987 y la actividad gremial florecía especialmente en aquellos ámbitos laborales escasamente coloni-

\footnotetext{
6 En 1944, se sanciona el Estatuto del Peón de Campo, extendiéndose los derechos laborales del ámbito urbano al rural, con especial impacto en los ingenios azucareros. En 1949, el Presidente Perón expropia los latifundios que empresarios azucareros tenían en la Puna jujeña para forzar a los pobladores a asistir anualmente a la cosecha de caña de azúcar a cambio del derecho de residencia. Entre los latifundios expropiados se encontraba el del dueño del ingenio San Martín del Tabacal, que contenía en su interior la totalidad de la jurisdicción de la Comisión Municipal de Yavi (RUTLEDGE, 1987, p. 211-230).
} 
zados por el sindicalismo, como es el trabajo agrario temporario. La creciente mecanización de la cosecha de caña de azúcar junto al agotamiento del modelo económico vigente enfrentó a Fermín y a las familias zafreras con un deterioro acentuado de sus ingresos. La sindicalización de los zafreros para obtener iguales derechos laborales que los trabajadores de la fábrica fue la propuesta de sus “amigos gremialistas”. Secundado por Anselmo, su cuñado, Fermín fue protagonista de la creación de un nuevo sindicato.

Siempre referenció al Sindicato del Surco como el primer espacio en donde se "metió en política", “aprendió a trabajar políticamente”, a "manejar políticamente" y a defender sus derechos y el de "la gente humilde". La política siempre fue pensada y representada por Fermín y el resto de mis interlocutores como poseyendo un lenguaje, prácticas, personas, espacios, tiempos y lógicas de vinculación particulares. Un ámbito sofisticado que demanda conocimientos que ellos no poseen. "Meterse en política", es decir pasar a ser un "político", es una elección personal e implica tiempo, trabajo y exponerse a la opinión pública. Pero sólo tiene éxito quien sabe manejar las lógicas y lenguajes propios de la política. De ahí, la necesidad de "amigos": dirigentes formados que los apadrinen, guíen y formen en "el manejo político".

Uno de los “amigos” de Fermín fue un diputado salteño de la Unión Cívica Radical, que asesoró e intermedió por el Sindicato del Surco en la Legislatura (poder legislativo) provincial. Al igual que su hermano, en las elecciones de la década de 1980 Fermín votó a Raúl Alfonsín y a los candidatos "radicales"7. Pero en la actualidad, se define como "peronista-peronista", comolos ancianos yaveños, esos que fueron "liberados por Perón”, con las reformas de la década de 1940, y a quien aún son leales. Herederos de esos derechos institucionalizados, gran parte de los hijos y nietos de esa generación de zafreros también se definen como "peronistas", pero en ellos esa lealtad no es necesariamente transitiva a los actuales candidatos “justicialistas". En su comportamiento electoral, vínculos con referentes de otros partidos pueden anteponerse a la adscripción partidaria. Varios dirigentes de la facción de Fermín, como

\footnotetext{
Desde mediados a fines del Siglo XX, la dinámica electoral argentina y jujeña se configuró fundamentalmente en torno a dos partidos políticos: la Unión Cívica Radical, cuyos seguidores son denominados "radicales" y el Partido Justicialista, integrado por los "peronistas" o "justicialistas".
} 
él mismo, "entraron a la política" a través de un "amigo radical" y emigraron a las filas del peronismo persuadidos por otro "amigo".

La incipiente experiencia gremial de Fermín se interrumpió con la crisis inflacionaria de 1989 y el cambio en sus estrategias de generación de ingresos. "La plata que ganábamos no alcanzaba. Un jornal no alcanzaba para un kilo de azúcar. Estando en el Ingenio, metí a mi familia en un camión y la mandé para Yavi. A los meses también me vine". Trabajar en el ingenio dejó de ser una alternativa. Conseguir "changas" - trabajos puntuales - pasó a ser su desafío para su subsistencia y la de su familia.

Permanecer en Yavi y disponer de tiempo libre lo predispuso a participar en el Centro Vecinal del pueblo y fue elegido presidente. Desde esa posición, conoció el "manejo político" municipal y se dio a conocer entre los referentes políticos locales.

En el 91' me meto en una campaña electoral. La empresa [el Ingenio San Martín del Tabacal] no daba más, no servía para trabajar. Un amigo de La Quiaca me dice: metámonos a la campaña electoral, laburemos, vos tenés capacidad, podemos manejar gente, pero hagamos las cosas bien. Entonces empezamos a trabajar políticamente. Hice campaña y pierdo las elecciones en Yavi. ¡Por cuatro votos! Pero entro como vocal.

Desde el retorno de la institucionalidad democrática en 1983, el Gobierno provincial y la Comisión Municipal de Yavi habían sido gobernadas por representantes del Partido Justicialista. Roberto, un dirigente de La Quiaca que llegó a ser vicegobernador, conducía la facción gobernante de Yavi y tenía gran influencia en la designación de los candidatos.

Hasta 1986, quienes residían en jurisdicciones de comisiones municipales solo votaban para cargos electivos nacionales y provinciales de los poderes ejecutivo y legislativo. Los comisionados municipales y los tres vocales integrantes del Concejo Deliberante eran designados por el gobernador con acuerdo de la Legislatura provincial. A partir de la reforma de la Constitución provincial de ese año, el comisionado pasó a ser elegido por los vocales y éstos por el voto directo de la población (KINDGARD, 2009, p. 135). Cada dos 
años se renueva la mitad de los integrantes del Concejo Deliberante y se elige al futuro comisionado. La nueva Constitución también redujo el tamaño de la Comisión Municipal de Yavi. El territorio original fue dividido en cuatro comisiones, quedando circunscripta la yaveña al pueblo y a once comunidades aledañas. La Comisión Municipal de Yavi pasó a ser un distrito electoral más pequeño, con relaciones más personalizadas.

La otra reforma institucional que cambió la dinámica política provincial fue la sanción, en 1991, de la Ley de Lemas. En este sistema electoral en cada votación y jurisdicción ocurrían dos plebiscitos simultáneos: al interior de cada "lema" (partido político o frente electoral) y entre lemas. Los "sub-lemas" o corrientes internas de los lemas podían presentar candidatos y competían entre ellos para definir los candidatos del lema. A su vez, los votos de cada sublema se sumaban contabilizando los sufragios obtenidos por el lema de referencia y competían contra los de otros lemas. Adriana Kindgard observa que esa reforma electoral fue impulsada por los dirigentes del Partido Justicialista jujeño para sobrellevar su "crisis de dispersión", ante la imposibilidad de consensuar candidaturas entre los dirigentes de sus 33 corrientes internas (2009, p. 139).

La escena política yaveña de aquella época siempre fue presentada por mis interlocutores como un asunto de "gente de afuera" y acotada a las elecciones, predominando la imagen de obediencia de los yaveños en votar a la lista oficial, la de Roberto. La crisis del peronismo y las reformas institucionales generaron oportunidades para que dirigentes locales ampliaran su base territorial apadrinando candidaturas en distritos vecinos. La política se tornó permeable a la entrada de novatos. Fermín fue uno de ellos. Su pasado sindicalista y su posición de presidente del Centro Vecinal de Yavi lo consagraban como candidato predilecto para competir contra el oficial.

Me metí en la política porque acá en el pueblo había un comisionado de la línea de Roberto y nunca se calentaba por hacer nada por Yavi. Era una cosa triste. Vivió como 14 años dentro del municipio. [...] Siempre ha sido la misma línea de ellos. A la gente nunca le ha dado participación, entonces por eso ha sido la bronca mía. No puede ser que el intendente sea el jefe del pueblo, entonces yo salgo a la oposición de él. 
Al relatar lo que lo motivó a involucrarse en el sindicato, Fermín enunció la "bronca" ante el "engaño" y "la estafa" de los empresarios azucareros. Fue un sentimiento semejante, surgido ante la inacción y la restricción a la participación de los yaveños de quienes gobernaban el municipio, lo que lo llevó a postularse en las elecciones. La indignación ante situaciones de injusticia es lo que siempre identificó como el móvil que lo impulsó a "meterse en política", para cambiar el estado de cosas en beneficio de la "gente humilde".

A pesar de las buenas intenciones que esgrimen quienes revisten papeles políticos, el rédito económico es la explicación más frecuente que los electores yaveños accionan para revelar lo que consideran sus verdaderas motivaciones. En una sociedad como la yaveña, en la que la subsistencia del grupo familiar es un desafío, acceder a un empleo estatal es el deseo y meta de gran parte de la población. Quienes asumieron cargos políticos reconocieron la mejoría económica que conlleva, pero se esforzaron en desmitificar el lucro económico que el resto de la gente denuncia.

En mi parecer, el incremento de los ingresos económicos de quienes se "meten en política" no se explica solamente por el salario que perciben, sino por el cambio de sus estrategias económicas. Fermín y otros dirigentes que asumieron puestos municipales incursionaron en emprendimientos de servicios (transporte de pasajeros, hostales, almacenes, etc.), para los que se precisa licencia municipal. Las estrategias de reproducción social de los yaveños tradicionalmente han sido pluriactivas, teniendo por eje lo agrario. En la trayectoria de quienes incursionan en política, pareciera que la capitalización diferencial que posibilita el salario sumado al acceso a la autorización municipal y a conocimientos de gestión inciden en la reorientación de sus estrategias económicas a emprendimientos de servicios, perdiendo peso lo agropecuario. Los más afortunados, finalizados sus mandatos consiguen reubicarse en puestos de baja jerarquía en instituciones o empresas estatales. Así, se delinea una de las vías de diferenciación y ascenso social en Yavi, pero no todos los comisionados han seguido esta vía. 
En su incursión en la política municipal, Fermín nuevamente estuvo acompañado por un "amigo", pero esta vez de una facción peronista contraria a Roberto. Los cuatro votos que lo separaron de la victoria siempre los presentó con cierto aire de proeza. Como novato en la política municipal y como candidato de una "línea" minoritaria, estuvo próximo a arrebatarle la victoria al candidato del vicegobernador.

Consagrarse como vocal municipal, fue el primer paso en la construcción de su facción política.

Como vocal, ahí sigo trabajando políticamente y en las próximas elecciones vengo y las gano. Ahí recién tomo yo la municipalidad como comisionado, dos años después. 92, 93 [como vocal y] 94, 95 era comisionado. En el 95' había elecciones. Ahí vuelvo a presentarme como candidato, le vuelvo a ganar. Estuve ocho años dentro de la municipalidad.

Fermín ha sabido valorar y producir su papel de hombre político y su lugar de ego en la facción que creó y conduce a través de su narrativa y de sus lógicas de acción. Quien se presentó como candidato en 1993, fue Anselmo, su cuñado. Es elocuente como en el relato de Fermín se confunde la figura del candidato con la suya, pues la candidatura de Anselmo no solo fue su idea, sino también su estrategia para consagrar a su cuñado como vocal y a sí mismo como comisionado municipal.

Yo pongo un candidato, que lo puse a mi cuñado, que en paz descanse. Entonces, cuando nosotros hacemos una oposición a la Comisión Municipal, la ganamos. Ahí manejo yo la Comisión Municipal. Yo hago un negocio con él, para yo ser comisionado. Negocio con los otros dos vocales que me voten a mí y ahí me votan como comisionado. Ahí tomo la Comisión Municipal.

Al revisitar las conversaciones con Fermín, destaca la escasa alusión a su segunda candidatura. Al parecer, su victoria era previsible. Al tiempo de asumir su primera gestión como vocal tuvo un "roce político" con su amigo de La Quiaca, quien lo acompañó en su primera campaña electoral. "En la 
política siempre es bueno tener un alero", me explicó para justificar su realineamiento y "amistad" con Roberto, quien le enseñó qué era el peronismo y lo hizo "peronista-peronista".

Entre 1987 y 1998, la crisis de dispersión del peronismo jujeño se proyectó en la ingobernabilidad de la provincia con la sucesión de ocho gobernadores de ese partido político (KINDGARD, 2009). En contraposición, las alianzas y vínculos que Fermín estableció con los referentes de las corrientes que se alternaron en el gobierno provincial y con los actores locales le posibilitaron consolidar su facción. Así surgió un nuevo hombre fuerte en la política yaveña.

\section{PRODUCIR Y GESTIONAR LA FACCIÓN}

Desde 1993, la facción de Fermín ganó prácticamente todas las elecciones. Los plebiscitos solían enfrentar peronistas y radicales, pero desde 2005 se dirimen entre facciones peronistas que compiten a través de diferentes frentes electorales 8 .

Fermín no volvió a candidatearse ni ha ocupado cargos en la Comisión Municipal; solo asumió puestos en la Comunidad Aborigen de Yavi, creada a partir de la estructura del Centro Vecinal a fines de la década de 1990. Sin embargo, en los testimonios de dirigentes de su facción y de los opositores siempre fue reconocido como la persona más influyente en la política yaveña. Pero, cómo se (re)produce la facción como dominante y a Fermín en la posición de ego. A continuación, analizo los factores y lógicas que posibilitaron que la facción que él conduce ampliara su base electoral y se reprodujera en el tiempo sobreviviendo a las disputas inherentes a la política.

\footnotetext{
La facción de Fermín ha ganado prácticamente todos los comicios, oscilando el apoyo electoral entre 49,3 y el 59,5 \% de los votos. En 2013 salieron en segundo lugar con 39\% de los sufragios para la categoría vocales municipales. En los últimos 15 años el apoyo electoral recibido por los candidatos radicales no ha superado el 12\% (TEPPJ, 2016).
} 


\section{La producción de seguidores}

La construcción y ampliación de la facción que conduce Fermín se proyectó sobre sus redes de pertenencia y la de sus seguidores y ocurrió en relación a la reconfiguración de las tramas sociales locales. En su primera candidatura convocó y movilizó el apoyo de sus parientes, en particular de su cuñado y de su hermano, y el de sus vecinos, muchos de los cuales habían confiado en él para presidir el Centro Vecinal. También movilizó su prestigio y los vínculos producidos en sus años de sindicalista con sus ex colegas de la zafra, en el "campo", y, con sus "amigos gremialistas", en el ingenio, quienes patrocinaron su campaña electoral. Parte significativa de los yaveños continúa emigrando estacionalmente a los ingenios azucareros. El proselitismo electoral en dichos lugares y el ofrecimiento de traslado a Yavi para el día de comicios continúan siendo prácticas desplegadas por los candidatos.

Convertirse en comisionado municipal significó acceder al control de la distribución de los recursos públicos y tornarse más (re)conocido. Gente de su confianza, en muchos casos familiares, ocuparon cargos municipales. Desde ese lugar, así como desde el almacén que regentea su esposa y desde el remise que más tarde compró para realizar servicios de viajes, conoció a muchas personas, realizó favores y se ganó el "cariño" de la gente, ése que hoy se refleja en los 120 ahijados/as que apadrina junto a su esposa.

Conforme analizo en otra publicación (COWAN ROS, 2017), en una localidad pequeña como la yaveña, en la que las relaciones múltiples y personalizadas impregnan las interacciones cotidianas, un candidato difícilmente será percibido solo como "político" por los pobladores. Existen otros principios a partir de las cuales lo reconocen y sitúan en sus redes de pertenencia ("pariente", "vecino", "compadre", etc.). Durante la campaña electoral las adhesiones se accionan de compromisos contraídos de prestaciones realizadas en otras esferas de la vida social y también en la política. Esas (contra)prestaciones son enunciadas como "ayuda [a los electores] por apoyo [al candidato]" y pueden adquirir trazos de reciprocidad difusa o balanceada conforme la proximidad o distancia con la que se perciban los protagonistas. 
Conforme se deduce de la cita 1, Fermín comprendió que en política no sólo es importante lo que se da [o se dice], sino cómo se da [o se dice], "la performance asociada al acto", conforme observa Javier Auyero (2001, p.135). "Hablar con respeto" y "tratar bien a la gente" fueron aspectos distintivos de su (nueva) forma de "trabajar políticamente", que parece haber despertado el interés de sus seguidores.

La red vincular sobre la que se construyó la facción se amplió y diversificó conforme se sumaron nuevos dirigentes. El núcleo de la facción está integrado por referentes de nueve de las doce comunidades que componen la jurisdicción. Fermín siempre resaltó que dio "participación” a los pobladores de "el campo", llevando la política más allá de los límites del pueblo. Ese accionar se correspondió con la reconfiguración de las lógicas organizativas y representativas de los yaveños derivadas de la actualización de la cuestión indígena. La Constitución Nacional de 1994 inauguró el reconocimiento de los pueblos originarios como sujetos de derecho colectivo y supeditó la entrega de los títulos de las tierras a la comunidad indígena, figura jurídica reconocida por el estado. A inicios de la década de 2000, la totalidad del territorio y de la población de Yavi, incluido el pueblo, estaban divididos en doce comunidades indígenas, con sus respectivos representantes y personerías jurídicas, y era creciente el activismo por el reclamo de la titularidad de las tierras.

En diferentes ocasiones Fermín asumió cargos en la Comunidad Aborigen de Yavi, sin embargo en nuestras charlas nunca adscribió espontáneamente a alguna de las identidades étnicas originarias ni se proclamó promotor de esa causa. Situaba a los dirigentes indígenas locales en la "oposición" y desconfiaba de sus intenciones. Es que en Yavi, como en otras localidades de Jujuy, una nueva camada de dirigentes indígenas contrapone a la "vieja política" otro modo de gobierno, referenciado en la cosmovisión andina y que define a las comunidades como ámbitos de consulta y control de la administración pública. Pero, rara vez los miembros de las comunidades consiguen comportarse corporativamente ante eventos electorales, las redes políticas suelen permearlos y fragmentarlos. 
La tensión entre Fermín y los dirigentes indígenas locales se originó en 1999, cuando éstos, a través de una organización campesino-indígena patrocinada por una ONG de desarrollo rural, impulsaron la creación de un consejo consultivo. Éste fue definido como un ámbito de interlocución y cooperación entre las autoridades municipales y los representantes de las comunidades indígenas para que estos últimos tuvieran injerencia en la administración de los recursos públicos y, de ese modo, transparentar su distribución. Las críticas emanadas por algunos de los integrantes del nuevo espacio inhibieron a Fermín y a sus seguidores de aceptar la convocatoria. En 2002, en el marco de la implementación de un programa nacional de empleo transitorio ejecutado a través de los órganos de gobierno municipales, desde el Estado nacional se reglamentó la creación de instancias consultivas para la ejecución del programa. Las autoridades municipales de Yavi debieron reconocer al consejo consultivo. Durante su gestión como comisionado entre 2003 y 2005, Tirso, yerno de Fermín, se aproximó a los dirigentes indígenas y sumó a uno de ellos como secretario de desarrollo agropecuario de la Comisión Municipal. Diplomado en gestión pública y avezado en el lenguaje del desarrollo, Tirso tuvo mayor entendimiento con los dirigentes indígenas que Fermín. Dos años después, el dirigente indígena fue candidato por la facción oficial y ganó la conducción del gobierno local. El apoyo de parte de las bases de la organización campesino-indígena fue elocuente, aunque su conducción se fragmentó.

La incursión de Tirso en la facción movilizó otra red de filiación. Referente de una iglesia evangélica, de creciente expansión en la región, supo sumar a miembros de su congregación. Durante su gestión, tres de los cuatro vocales municipales eran evangélicos, en una jurisdicción donde predomina la práctica del catolicismo.

Si hasta la incursión de Fermín en la escena local, la política era cosa de "gente de afuera", su acceso a la Comisión Municipal convergió con un cambio en el acceso de los yaveños a la política y al órgano de gobierno municipal.

Yo he empezado a dar participación a toda la comunidad, a trabajar conjuntamente con todas las comunidades. ¡No solo con Yavi! Para 
que la gente tenga fuentes de trabajo, no te digo para llenarse de plata, pero al menos para sobrevivir. Que conozca un jornal del municipio. ¡El gobierno jamás le había dado participación con un jornal a la gente del campo!

Entre las décadas de 1990 y 2000, la precarización de las condiciones de vida de los yaveños multiplicó el número de familias con "necesidades". Para Fermín y para muchos pobladores de la región, las características agroclimáticas de la Puna impiden que las familias subsistan únicamente con la producción agropecuaria. Entienden que generar puestos de trabajo es la única opción para mejorar la calidad de vida de la población y creen que ésa debe ser la meta de la gestión municipal.

En la década de 2000, la proliferación de programas públicos de promoción social que operó concomitantemente a la política nacional de descentralización, que delegó la ejecución de programas sociales en los municipios, se expresó en Yavi como la primera generación de políticas sociales en alcanzar el territorio. Las funciones de la Comisión Municipal se resignificaron y profesionalizaron, colocándola en el centro de la demanda de "ayuda" de los pobladores. Ese fenómeno se tradujo en un crecimiento exponencial de recursos públicos distribuidos por esa entidad y la sistemática generación de nuevos puestos de trabajo municipales, con la consecuente imbricación entre las estrategias de reproducción social de gran parte de los yaveños y el órgano de gobierno local (COWAN ROS, 2014, p. 614-615) ${ }^{9}$. La propuesta de Fermín de

\footnotetext{
Hasta 2003 seis personas trabajaban permanentemente en la Comisión Municipal (un comisionado, tres vocales, un secretario y un tesorero). En 2007 esa cifra se elevó a nueve, con la incorporación de un secretario de turismo, un secretario de obras y un secretario de desarrollo agropecuario. Aproximadamente 90\% del presupuesto municipal - "la coparticipación"- se destinaba a pagar salarios de los empleados de planta permanente, el remanente sumado a la escasa recaudación de impuestos y servicios municipales se destinaba a la contratación temporaria de 30 personas. En 2011, las autoridades municipales estimaban que alrededor de 60 personas habían trabajado a lo largo del año, bajo la modalidad de contrato, en la construcción de edificios públicos, repavimentación de la ruta y extensión de red eléctrica, a partir de proyectos públicos y acuerdos con empresas privadas. La diferenciación y ampliación de las acciones realizadas en la Comisión Municipal también se observa en la diversidad de programas que ejecuta con financiamiento nacional y provincial: vivienda, infraestructura pública, alimentarios y microemprendimientos turísticos y agropecuarios. En 2007, 100 personas recibían la remuneración de programas de empleo transitorio, 180 familias recibían mensualmente un bolsón de alimentos y 35 personas tenían pensiones graciables por invalidez o madre con más de siete hijos. Si se considera que en la jurisdicción existen aproximadamente 350 grupos domésticos, se evidencia la creciente imbricación entre las estrategias de reproducción social de los yaveños y las acciones de la Comisión Municipal.
} 
"dar participación a la gente” converge con ese fenómeno. Haber experimentado, al igual que muchos yaveños, la desarticulación de sus estrategias de vida probablemente lo predispuso a valorar y refuncionalizar la Comisión $\mathrm{Mu}$ nicipal como proveedora de empleo.

Las transformaciones relatadas se imbricaron y potenciaron con el accionar de miembros de ONGs y de la Iglesia Católica que promovieron nuevos dirigentes, modalidades organizativas y la intervención a través de proyectos de promoción social.

Antes los abuelos eran analfabetos. En cambio, hoy los chicos son más despiertos, tienen información, escuchan radio, tienen televisión, están estudiando en La Quiaca y terminan la secundaria. Hoy la gente es muy pícara para votar y saben quién gobierna bien y quién gobierna mal. Antes con un pequeño locro, unos cuantos vinos y ya estaba toda la campaña. Hoy no. La gente abrió los ojos. [Dicen:] queremos saber qué proyecto tiene usted, cómo va a colaborar con los proyectos que tenemos.

Fermín y Tirso, que se perfila como su sucesor, han sabido interpretar y adecuar sus propuestas a las transformaciones sociales, políticas e institucionales que impactaron en los modos de vida y en el comportamiento político de los yaveños y, probablemente sin saberlo, también han sido sus promotores.

\section{Gestionar la facción: "trabajo administrativo" y "trabajo político"}

En 1999, reencauzadas las disputas entre los dirigentes peronistas jujeños, se derogó el sistema electoral de lemas (KINDGARD, 2009, p. 175). Los candidatos partidarios pasaron a elegirse en plebiscitos de afiliados, realizados antes de las elecciones generales. Gestionar las ambiciones de los referentes peronistas locales, pasó a ser uno de los desafíos de Fermín para mantener unida la facción.

Todos estos chicos que han pasado después que yo salí del municipio, todos han sido mis dirigentes, dirigentes nuestros, que yo los apoyé y 
siempre ellos me han apoyado a mí. Todos los comisionados que han pasado han sido gente mía. Yo les di la facultad para que aprendan y conozcan. No he sido mezquino para nada.

El otro sentido que moviliza Fermín cuando enfatiza que dio "participación a la gente" remite a la circulación por los cargos municipales de referentes de las comunidades de la jurisdicción. A partir del año 2001, propuso que en Yavi los candidatos del Partido Justicialista fuesen elegidos por los dirigentes locales y no se repitan candidaturas. De no existir acuerdo, los aspirantes competirían en las elecciones internas partidarias. Pero, como se desprende de la cita 10, la opinión de Fermín parece tener un peso decisivo en la construcción y definición de candidaturas.

La rotación de candidatos evidencia relativa eficacia para administrar las ambiciones de los dirigentes, pues a todos les llegará su turno. Pero, la forma como cada uno pondera su compromiso y trabajo invertido en la facción y los derechos que de ellos derivan (acceso a cargos, candidaturas, servicios municipales, licencias y/o beneficios de algún programa) no siempre son interpretados o correspondidos por el resto. Desentendimientos de ese tipo derivaron en peleas al interior de la facción. Quienes sintieron que podían movilizar suficiente apoyo electoral se aventuraron a competir en las elecciones internas partidarias, pero nadie tuvo éxito. Otros emigraron a las filas de la "oposición", el hermano de Fermín y el hijo de Anselmo entre ellos. Conforme observa Moacir Palmeira, la adhesión política está vinculada a "lealtades primordiales", pero existe cierta autonomía entre ambas, pues la "lealtad al voto" se adquiere a través de los compromisos generados en el marco de prestaciones (PALMEIRA, 1992, p. 27). Las divisiones familiares y las habladurías de la gente son la faceta dolorosa de la experiencia política de Fermín, pero no lo han desmotivado.

Un aspecto distintivo de la cita 10, que también se observa cuando Fermín recuerda la candidatura de Anselmo (cita 6), es la producción retórica de su lugar de ego en la facción a través de personalizarse en la figura de los candidatos o de atribuirse la pertenencia de las personas que la in- 
tegran. Ese tipo de narrativa remite a una forma de experimentar y vivir la política, que técnicos de ONGs y algunos dirigentes indígenas y religiosos cuestionan por personalista y autoritaria, referenciándola con la "vieja política". Pero en Yavi, como en otras localidades del país, el léxico y las prácticas políticas se renuevan. Entre las expresiones de esos cambios retóricos destaca el paso del individuo al colectivo. También se observa la incorporación del lenguaje y los dispositivos de acción de la promoción social, como ser trabajar a través de "proyectos" y la propia idea de "participación". Fermín, más que un propiciador de esos cambios, parece adecuarse a las transformaciones en curso. Nótese cómo en la cita 10 su narrativa oscila entre el sujeto individual y el colectivo, evidenciando características, con sus pliegues y contradicciones, de la facción que conduce.

Otro de los dispositivos para la reproducción de la facción y de las posiciones y jerarquías en ella instituidas es la diferenciación del quehacer de sus miembros, según los saberes que poseen: en cuanto algunos se ocupan del "trabajo administrativo", otros se abocan al "político".

El "trabajo administrativo" refiere a las labores propias de la gestión municipal, las cuales han desplazado su eje hacia la ejecución de programas sociales. A diferencia de la imagen de la política de la década de 1980 que retratan los yaveños, en la actualidad la labor del comisionado es visible todo el año, atendiendo a las solicitudes de trabajo y de apoyo a los proyectos de los miembros de las comunidades indígenas. "Visitar a la gente, ver lo que necesitan y qué es lo que hay que hacer con cada comunidad" es la pauta de trabajo que Fermín transmite a "sus dirigentes".

Junto a la gestión de programas de promoción social un nuevo lenguaje, tareas administrativas, manejo de recursos informáticos y un universo de interlocutores estatales (técnicos de la institucionalidad pública nacional y provincial) pasaron a ser parte del cotidiano de los comisionados municipales y a demandarle saberes específicos. Con apenas siete años de escolaridad, Fermín percibió los desafíos que la gestión municipal impone a los de su generación. Lejos de ver en los jóvenes una amenaza a su posición, en sus relatos siempre los valoró y complementó con su figura. 
¿Si el "trabajo administrativo" es responsabilidad de "sus dirigentes”, cuál es el papel que Fermín se reserva como ego de la facción? "Hacer política” o "trabajar políticamente" son expresiones que en el sentido común yaveño valoran negativamente el modo de gestionar la cosa pública, cuando se percibe arbitrariedad en la distribución de los recursos. En las anécdotas de Fermín, esas expresiones adquirían otro sentido. “Trabajar políticamente” refería a las acciones para armar listas y "negociar cargos", como cuando narró su consagración como comisionado (cita 7), "conducir gente" (movilizar y mantener las adhesiones del electorado) y "pelear y ganar espacios". Aludía a sus estrategias de disputas y alianzas para mejorar posiciones en la jerarquía partidaria y acceder a más recursos para volcarlos a la gestión del gobierno municipal, incluso con lógicas no siempre compartidas o comprendidas por los electores. Remitía al despliegue de estrategias, siempre con algo de "picardía", que le hacían pensar y vivir la política con la pasión con la que se juega un "partido de fútbol".

Los sentidos y tareas que Fermín y sus seguidores agencian a la idea de "trabajo político" presentan similitudes con las observaciones de Julieta Gaztañaga para el caso del Partido Justicialista de la provincia de Entre Ríos. Ese tipo de tarea es reservada para los "profesionales de la política" y gravita en la articulación de relaciones interpersonales e institucionales de cara a la producción de obras políticas, que de otra forma no ocurrirían. Tiene un carácter extendido en el tiempo y multisituado, pues articula diferentes niveles de gobierno (GAZTAÑAGA, 2010). A lo largo de su trayectoria, el "trabajo político" de Fermín se ha centrado en la construcción de alianzas políticas en Yavi y a nivel provincial para conseguir recursos y viabilizar la gestión del gobierno municipal. En los últimos años, esa tarea ha adquirido nuevas dimensiones de la mano de Tirso, conforme analizo a continuación.

\section{Política provincial y producción de estatalidades}

En sus primeros años en la Comisión Municipal, Fermín percibió que es bueno tener "un alero político", es decir alinearse con un dirigente 
bien posicionado en la jerarquía partidaria, para modificar el escaso capital político que representa el electorado yaveño, 0,2\% del provincial (TEPJ, 2017). Esa lógica posibilitó acceder a recursos puntuales, pero no alteró su posición subalterna en la política provincial.

Entre los yaveños existe la percepción de que la Puna históricamente ha sido marginada del resto de la provincia. En la política eso se expresa en la escasa participación de los puneños en los cargos provinciales de gobierno y en los escasos recursos públicos que reciben. Los dirigentes políticos provinciales, incluso los del mismo partido, son caricaturizados como alegres y cordiales cuando visitan la jurisdicción para captar apoyo para sus candidaturas, pero cuando asumen el cargo desconocen o carecen de tiempo para recibir a los yaveños.

La inequidad del vínculo con los dirigentes provinciales también la experimentan otros referentes puneños. En 1998, un dirigente de la segunda ciudad en importancia de la Puna propuso crear una nueva "corriente" peronista en la región, pues quienes conducían la existente eran obsecuentes con los dirigentes de la capital provincial. Los referentes yaveños adhirieron para "tener más peso, presentar proyectos y presionar donde haya que presentarlos”. Tramitaron la personería jurídica de la Asociación de Municipios, denominación de la nueva corriente, para gestionar financiamiento y reclamaron representación entre los candidatos a diputados provinciales. Demoró casi una década que la conducción provincial del Partido Justicialista aceptara la solicitud a condición de que en las próximas elecciones ganarán un distrito urbano, que implicaba arrebatárselo a la corriente oficialista. En 2007, se cumplió la meta, pero el impulsor de la nueva "corriente", que se perfilaba como candidato, falleció en un accidente al poco tiempo. En 2009, Tirso ocupó un lugar en la lista de diputados provinciales y ejerció el cargo entre 2009 y 2013. La Asociación de Municipios llegó a controlar el 75\% de las jurisdicciones rurales de la Puna y una intendencia de la dos existentes. Esa representación poco modificó su capital político: en 2015, el electorado puneño representaba 6,6\% del padrón provincial (TEPPJ, 2016). 
Para Tirso, acceder a la Legislatura provincial supuso el descubrimiento de otra faceta del "trabajo político", la legislativa, y otro modo de hacer política, más hostil, con lógicas, éticas e intereses diferentes a los suyos y estructurada bajo la disciplina partidaria. Reducía su vocación emprendedora a un voto obediente con los proyectos oficialistas. La función legislativa no resultó inmediatamente útil para Tirso, sin embargo supo reconocer y accionar otro capital político: la investidura de diputado provincial. "Al llegar a Buenos Aires con una chapa de diputado provincial, era otra la persona que iba, las puertas se abrieron un poco". Consiguió la repavimentación de la ruta de acceso a Yavi y la extensión de luz eléctrica a comunidades indígenas.

Durante su gestión como comisionado municipal de Yavi había implementado un proyecto de desarrollo productivo, pero percibió la necesidad de ampliar la escala de intervención para tornarlo viable. En 2009, convocó a los otros comisionados municipales del departamento de Yavi para ejecutar un plan de desarrollo micro regional. La personería jurídica de la Asociación de Municipios fue utilizada como contraparte de las agencias de financiamiento para ejecutar los primeros proyectos. En 2014, en un evento en un ingenio azucarero se enteró que desde el Programa de Servicios Agrícolas Provinciales (PROSAP) del Ministerio de Agricultura, Ganadería y Pesca de la Nación se convocaba a los gobiernos provinciales a presentar hasta tres propuestas de desarrollo competitivo de micro regiones. La operatoria del programa pauta que la unidad ejecutora debe ser una "asociación Ad-Hoc", integrada por instituciones estatales y privadas, poseer personería jurídica con atributos de entidad pública para firmar contratos con el Gobierno Nacional y ejecutar planes de desarrollo. En la propuesta, el Gobierno provincial debe incluir el aval de las autoridades municipales que integrará cada micro región.

Con el asesoramiento de técnicos del PROSAP y junto a las autoridades de las otras cuatro comisiones municipales del departamento de Yavi, Tirso impulsó la formulación de una propuesta de desarrollo para la micro región. Convocó a referentes locales del Instituto Nacional de Tecnología Agropecuaria, la Secretaría de Agricultura Familiar de la Nación y la Secretaría de Turis- 
mo de Jujuy para brindar asistencia en los cinco proyectos (agricultura, ganadería, artesanía, turismo y gestión ambiental) que componen el plan de desarrollo y mejora competitiva, una adaptación de su proyecto original al formato demandado por el PROSAP. Finalmente, diseñaron el reglamento y organigrama de la futura entidad que ejecutaría el plan, denominada Micro región Yavi e integrada por cinco comisiones municipales. Restaba tramitar la personería jurídica, pero las autoridades del gobierno provincial no dieron su aval por considerar que ese tipo de institución no estaba contemplada en el organigrama de la administración pública provincial. Suponía crear una nueva figura estatal intermedia entre el gobierno provincial y los municipales. Tampoco apoyaron un proyecto de ley impulsado por Tirso para reglamentar dicha figura.

En diciembre del 2015, una coalición conducida por dirigentes de la UCR y secundada por miembros de una facción provincial del Partido Justicialista opositora al anterior gobernador asumió el Gobierno provincial. Ante el nuevo escenario, Tirso realizó gestiones con un referente justicialista integrante de la nueva coalición gobernante y consiguió la reglamentación de la personería jurídica de carácter público de la Micro región Yavi. La ejecución del plan de desarrollo, la cuarta experiencia del país y la primera de Jujuy, comenzó cuando escribía este artículo. Aquí, me interesa rescatar la agencia desplegada por Tirso en la redefinición de sus funciones como legislador y en el trabajo político que desplegó para la creación de una nueva institucionalidad y modo de gestión de recursos públicos en Jujuy. Lógicas de acción centradas en la producción de vínculos, consensos y apoyos, por dentro y por fuera de la institucionalidad y normativas existentes, que buscan sortear estructuras y jerarquías provinciales para suprimir intermediarios y movilizar recursos en pro de la gestión de los miembros de la facción y de la suya en el cargo que reviste.

El otro fenómeno relevante en la experiencia de Tirso como diputado provincial es la dificultad para proyectarse en la jerarquía política dado el escaso capital político que detenta como referente de una jurisdicción con insignificante peso electoral. Concluido su cargo retornó a Yavi y se insertó como coordinador del plan de desarrollo de la Micro región. La nueva institucionalidad le posibilitó reproducirse como profesional de la política. 


\section{La política como satisfacción}

Con el apoyo de Fermín, Tirso se perfila como su sucesor, pero el primero no pierde la pasión por la política. No prevé postularse como candidato a comisionado y considera remota la posibilidad de acceder a un cargo provincial, pero afirma: "yo voy a seguir, hasta que no dé más. A mí me gusta la política, me encanta”. ¿Por qué alguien que ya experimentó los sabores y sinsabores de la política, decide continuar sin aspirar a un cargo público?

Mirá, para mí, a veces, la política... ¿Cómo te puedo decir? ¡Es una cosa muy grande para uno! Se aprende mucho, a conocer muchas cosas, desde acá hasta la [capital de la] provincia, quizás hasta grandes lugares. En la Quiaca me conocen todos, voy a [la ciudad de San Salvador de] Jujuy, entro a la casa de gobierno [y me saludan] ¡Eh! ¿Cómo estás Fermín? La conozco de punta a punta y ellos también me conocen y eso es bueno. ¡Imaginate si yo no estaba metido en esto, hoy qué sería! Un triste habitante, nada más. No me conocería nadie. Pero, por lo menos, tengo esa opción, tengo ese recuerdo, de tener mucha gente amiga, mucha gente conocida.

Es difícil conocer con precisión los motivos iniciales de Fermín para incursionar en la política, pero es posible captar aspectos de su trayectoria que hoy valora y lo estimulan a continuar. Así como las trayectorias de las personas son dinámicas, sus motivaciones se actualizan con las experiencias vividas y nuevas posiciones asumidas.

En la política no solo se puede buscar "trabajar para la gente", fórmula con la que los dirigentes políticos suelen presentar públicamente sus motivaciones, o mejorar su posición económica, parecer de parte del electorado. La política también ofrece y puede vivírsela desde su dimensión recreativa y lúdica. Esto fue observado en jurisdicciones rurales (PALMEIRA; HEREDIA, 2010) y urbanas (AUYERO, 2001; QUIRÓS, 2011, entre otros). Cada dos años se acciona una disputa en la que los candidatos miden públicamente su astucia y, fundamentalmente, su prestigio.

Con su involucramiento en política, Fermín salió de ese circular entre el pueblo y el ingenio y conoció "grandes lugares", "gente importante" e hizo 
"amigos". Se convirtió en un hombre sobre el que circulan versiones antagónicas, pero todos lo conocen. A través de la política accedió a un mundo al que no todos acceden, se convirtió en otra (clase de) persona, que lo libró de ser "un hombre triste".

\section{CONSIDERACIONES FINALES}

La posición subalterna que ocupan los dirigentes yaveños en la escena política provincial, dado el escaso peso electoral de la localidad, es un factor que condiciona sus motivaciones y prácticas. Esa característica es estructural y entiendo que es generalizable a otras pequeñas jurisdicciones, especialmente las rurales, adquiriendo relevancia en la comprensión de la dinámica de la política en dichos lugares.

Los yaveños que incursionan en política saben que el mayor puesto al que pueden aspirar es el de comisionado municipal y, en la mayoría de las veces, por apenas dos años. Ese horizonte cercano en la carrera política modela sus aspiraciones y, en la mayoría de los casos, los inhibe hacer de la política una profesión. Existe una multiplicidad de motivos que predisponen a las personas a involucrarse en política. Destaco la dimensión lúdica y el prestigio que puede obtenerse a través de ella, por ser menos tematizados en la literatura académica. Ambos hacen a la vida de esas personas, a cómo son (re)conocidas y valoradas en sus localidades. Forman parte de sus estrategias de reproducción social, pues involucrarse en política es una forma de construir y/o validar una reputación y una posición, tanto individual como familiar. La política no sólo permite diferenciarse de sus pares en términos económicos, sino también simbólicos, a través del (des)prestigio que se genere. De ahí la pertinencia de la metáfora del "juego político", pues se puede ganar o perder y muchos por las "habladurías de la gente" han abandonado el juego.

En Yavi se observa que las transformaciones en las prácticas políticas se encuentran en relación a procesos que operan en otras esferas sociales. Las 
visiones y prácticas difundidas por activistas indígenas y por agentes de desarrollo gradualmente permean y redefinen la política local. Matías Berger también observó la imbricación entre prácticas políticas de dirigentes campesinos y las lógicas de intervención de técnicos del Programa Social Agropecuario en la provincia de Formosa (BERGER, 2014). En los ámbitos rurales de Argentina las acciones de desarrollo rural patrocinadas por referentes de agencias públicas y privadas destacan entre las que tienen mayor incidencia en la población. Sea por la circulación de personas por las diferentes esferas sociales y/o por las visiones de mundo y los saberes sobre gestión de proyectos que los agentes de desarrollo difunden entre la población local, la escena política se actualiza a partir de los lenguajes, prácticas y, en algunos casos, referentes de ámbitos no definidos como políticos por las personas. Este fenómeno reafirma la necesidad de estudiar la política en su imbricación con otras esferas sociales y reconsiderar las perspectivas analíticas que se centran en su autonomía.

Una última reflexión merece el papel de los dirigentes políticos locales en la producción de (nuevas) instituciones que modelan cómo se expresa lo estatal en los espacios locales y cómo eso se vincula a su (re)producción como profesionales de la política. Las nuevas secretarías en el órgano de gobierno municipal, la Asociación de Municipios, así como la nueva institucionalidad creada para la Micro región surgieron por iniciativa de los dirigentes políticos locales para organizar y viabilizar su gestión de gobierno, movilizar recursos a sus jurisdicciones y alterar su escaso capital político electoral a través de realizar alianzas con referentes de instituciones situados en diferentes niveles estatales. La Micro región destaca por ser una entidad paraestatal no prevista en el organigrama oficial de la Provincia, que pone en relación a instituciones públicas y privadas, para dinamizar la gestión de las autoridades municipales. La creación de esa nueva institucionalidad no es sui generis, resulta de la adaptación y resignificación de marcos normativos existentes y de la creación de nuevos. Evidencia la creatividad que se despliega en los "márgenes del estado", donde otras lógicas colonizan a las prácticas estatales instituidas (DAS; POOLE, 2008, p. 24). Al igual que 
lo observado en el párrafo anterior, de esa interacción resultan prácticas híbridas que (re)definen las estatalidades.

El caso nos convoca a relativizar la jerarquía y el ejercicio de poder unidireccional y descendente con la que acostumbramos pensar la política y lo estatal (nacional $\rightarrow$ provincial $\rightarrow$ municipal), para reconocer la existencia en sus diferentes niveles de cierto margen de resignificación y producción de nuevas estatalidades. Ese margen de creatividad y producción de lo estatal se encuentra en relación al trabajo político desplegado por los dirigentes locales para revertir y/o compensar el escaso capital político que significa el caudal de votos en una pequeña localidad cuando se desea disputar posiciones en escenarios más amplios.

\section{REFERENCIAS}

1. AUYERO, Javier. La política de los pobres. Las prácticas clientelísticas del peronismo. Buenos Aires: Manantial, 2001.

2. BALBI, Fernando; ROSATO, Ana. Introducción. In: BALBI, Fernando; ROSATO, Ana (Org.). Representaciones sociales y procesos políticos. Estudios desde la antropología social. Buenos Aires: Antropofagia, 2003, p. 1-30.

3. BERGER, Matías. Nociones de representación y organización en disputa. Revista Avá, PAS-UNM, n. 21, 2014, p. 85-147.

4. COWAN ROS, Carlos. La trama de lo social. Familia, vecindad y facciones en la producción de prácticas políticas en comunidades aborígenes de la Puna argentina. Madrid: Editorial Académica Española. 2013.

5. COWAN ROS, Carlos. Quando o "beneficiário" se personaliza: (re)significação de programas de promoção social em comunidades andinas. Revista Sociedade e Estado, UnB, v. 29, n. 2, p. 607-633, 2014.

6. COWAN ROS, Carlos. Política, modos de vida y sociabilidad en una pequeña sociedad rural. Mundo Agrario, FHCE-UNLP, v. 18, n. 37, e. 046, abril 2017.

7. DAS, Veena; POOLE, Deborah. El estado y sus márgenes. Etnografías comparadas. Cuadernos de Antropología Social, FFyL-UBA, n. 27, p.19-52, 2008.

8. GAZTAÑAGA, Julieta. El trabajo político y sus obras. Una etnografía de tres procesos políticos en la Argentina contemporánea. Buenos Aires: Antropofagia. 2010. 
9. GOODWIN, Jeff; JASPER, James; POLLETA, Fancesca. The return of the repressed: the fall and rise of emotions in social movement theory. Mobilization: An International Journal, v. 5, n. 1, p. 65-83, 2000.

10. INDEC. Instituto Nacional de Estadísticas y Censos. Censo nacional de hogares, población y vivienda 2010: censo del Bicentenario: resultados definitivos, Serie B, n. 2. 1. ed. Buenos Aires: INDEC, 2012.

11. JOSEPH, Gilbert; NUGENT, Daniel. Cultura popular y formación del estado en el México revolucionario. In: JOSEPH; NUGENT (Comp.) Aspectos cotidianos de la formación del Estado. La revolución y la negociación del mando en el México moderno. México: Nueva Era, p. 31-52, 2002.

12. KINDGARD, Adriana. La política jujeña en los noventa: partidos y actores de poder. In: LAGOS, Marcelo. Jujuy bajo el signo neoliberal. S.S. de Jujuy: EdiUnju, 2009.

13. MAYER, Adrián. La importancia de los cuasi-grupos en el estudio de las sociedades complejas. In: BANTON, Michael (Comp.) Antropología social de las sociedades complejas. Madrid: Alianza Editorial, p. 108-133, 1980.

14. PALMEIRA, Moacir. Voto: racionalidade ou significado? Revista Brasileira de Ciências Sociais, n. 20, ano 7, p. 26-31,1992.

15. PALMEIRA, Moacir; HEREDIA, Beatriz. Política Ambígua. Rio de Janeiro: Relume Dumará, 2010.

16. QUIRÓS, Julieta. El porqué de los que van. Peronistas y piqueteros en el Gran Buenos Aires. Buenos Aires: Antropofagia, 2011.

17. RALPH, Nicholas. Segmentary factional political systems. In: SWARTZ, Marc; TURNER, Victor; TUDEN, Arthur (Org). Political Anthropolgy. Chicago: Aldine Pub. Co., 1966, p. 49-60.

18. RUTLEDGE, Ian. Cambio agrario e integración. El desarrollo del capitalismo en Jujuy 1550-1960. Buenos Aires: ECIRA, FFyL, CICSO, UBA y MLAL, 1987.

19. TEPPJ. Tribunal Electoral Permanente en la Provincia de Jujuy. Resultados electorales. Disponível em: <http://bit.ly/2CDFIac> Acceso em: 3 